\title{
Effects of Sea Salts on Induction of Cell Proliferation in Liquid Cultures of Mangrove Plants, Sonneratia caseolaris and S. alba
}

\author{
Raiki Yamamoto $^{1}$, Yoshifumi Kawana ${ }^{1}$, Reiko Minagawa ${ }^{2}$, Hamako Sasamoto ${ }^{2}$ \\ ${ }^{1}$ Graduate School of Environment and Information Sciences, Yokohama National University, Yokohama, Japan; ${ }^{2}$ Faculty of Envi- \\ ronment and Information Sciences, Yokohama National University, Yokohama, Japan. \\ Email: sasamoto@ynu.ac.jp
}

Received December $1^{\text {st }}, 2010$; revised December $13^{\text {th }}, 2010$; accepted December $29^{\text {th }}, 2010$.

\begin{abstract}
The effects of five salt ingredients of sea water, $\mathrm{KCl}, \mathrm{NaCl}, \mathrm{CaCl}_{2}, \mathrm{MgCl}_{2}$ and $\mathrm{MgSO}_{4}$, on induction of cell proliferation in Sonneratia caseolaris were investigated. Proliferation was examined in tissue explants derived from such as leaves, cotyledons, and hypocotyls using a small-scale liquid culture method. Addition of 12.5-25 $\mathrm{mM}$ of $\mathrm{MgCl}_{2}$ was unique in stimulating cell proliferation in all tissues of S. caseolaris. Otherwise, different effects of salts were observed among the three tissues. In hypocotyl culture, 25-50 mM of $\mathrm{NaCl}$ and $\mathrm{CaCl}_{2}$ stimulated cell divisions. Tolerance to $100 \mathrm{mM}$ of $\mathrm{MgSO}_{4}$ was observed in leaves. Three osmotically active compounds commonly used in tissue culture, sorbitol, mannitol and glycinebetaine, were also tested to assess the importance of osmotic effects on cell proliferation. No significant stimulation by these was observed over a wide range of concentrations. Data were compared with those of cotyledon cultures of another mangrove, S. alba, which exhibits no stimulation by $\mathrm{MgCl}_{2}$, stimulation by $\mathrm{KCl}$ and tolerance to $\mathrm{NaCl}$. Mechanisms for adaptation of mangrove plants to various and high salts were discussed by comparing the differences in reaction to salts in cultures of two Sonneratia mangrove species of the same genera growing different salt environment.
\end{abstract}

Keywords: Halophilic, Ions, Salt Tolerant, Sonneratiaceae, S. caseolaris

\section{Introduction}

Mangrove plants are mainly tree species that grow in tropical and subtropical brackish coastal regions. This group includes more than 100 species from different families [1]. Micropropagation of these species is needed for conservation of mangrove forests threatened by potential destruction [2]. Biotechnological breeding techniques such as somatic hybridization of trees $[3,4]$, may be promising tools for a year-round supply to replenish saplings and protect salty soil environment from desertification [5].

Studies on salt injury to crops are an increasingly important topic as soil damage from salt accumulation is proceeding [6]. Clarifying salt-tolerant mechanisms in cell and tissue culture systems of mangrove plants, and introduction of their characteristics through somatic hybridization or genetic transformation into crop species are also interesting themes to investigate. Mangrove plants offer both theoretical and biotechnological potential for improving plant growth in high salt environments, however, information on their physiology, biochemistry, and molecular biology remains limited. The development of in vitro culture systems is important for complementation of whole plant studies. In 2001, the successful establishment of a suspension culture from leaf explants of Bruguiera sexangula (Rhisophoraceae) was reported [7,8]. Protoplast fusion studies [9] and molecular biological work on salt-tolerance related genes has since been performed [10]. In order to expand our knowledge of mangroves, we recently established a suspension culture from cotyledon explants of the mangrove, Sonneratia alba (Sonneratiaceae), with subsequent study of its organogenic potential [11]. The effects of four main salt ingredients of sea water on S. alba were investigated and its halophilic nature and tolerance to $\mathrm{NaCl}$ were determined. They were compared with suspension cultures of $B$. sexangula, and tobacco BY-2 cells [12]. S. alba grows at the 
most seaside coast of the Iriomote Island, Okinawa, Japan [13], while B. sexangula grows in more in-land areas of Thailand [14].

To investigate the mechanisms of salt tolerance, a comparison of salt-tolerant and salt-intolerant plants, or cells of similar genetic background but different salt tolerance, is required. The latter investigation is problematic, because obtaining a specific tree mutant is very difficult. In the last few years, we have studied another mangrove plant, S. caseolaris, which is in the same genera as $S$. alba and shares its habitat in the in-land area of mangrove forests of Myanmar and Thailand [14]. Some cell proliferation was obtained from cotyledons and hypocotyls of S. caseolaris using the same hormonal conditions as for S. alba [11].

The objective of this study was to investigate the cell proliferation of different types of explants from S. caseolaris in response to $\mathrm{KCl}, \mathrm{NaCl}, \mathrm{CaCl}_{2}, \mathrm{MgCl}_{2}, \mathrm{MgSO}_{4}$, which are components of sea water. The results were compared with cell proliferation from S. alba cotyledon explants. One potential effect of adding salts to a culture system is the osmotic effect on cells. In order to assess the importance of osmotic potential on the proliferation of mangrove cells, several osmotically active compounds, sorbitol, mannitol and glycinebetaine, which are commonly used in tissue systems, were also tested. A smallscale liquid culture method [11] was used which minimized the volume of plant material required.

\section{Materials and Methods}

\subsection{Materials}

Fruits of S. caseolaris were collected at the Khu Khut, Songkla or at Khanom river Basin, Si Thammarat Province, Thailand, and those of S. alba were collected from Iriomote island, Okinawa, Japan. Aseptic procedures for S. alba were replicated from Kawana et al. [11]. Seeds of S. caseolaris were disinfected by treatment with detergent, soaked in $70 \%$ ethanol solution for $1 \mathrm{~min}$, washed with water, soaked in $3 \%$ sodium hypochlorite solution ( $\mathrm{NaClO}$ ) for $1 \mathrm{hr}$, and finally washed with sterile water three times.

Disinfected seeds were germinated on $5 \mathrm{ml}$ of $0.8 \%$ w/v agar medium (tissue culture grade, Wako Chemicals Co. Ltd) in $15-\mathrm{ml}$ test tubes under a $16 \mathrm{hr}$ photoperiod $\left(80 \mu \mathrm{mol} \mathrm{m} \mathrm{s}^{-1}\right)$, at $24^{\circ} \mathrm{C}$. After two to five months of culture, sterile hypocotyls and cotyledons were cut into two to three, $1 \mathrm{~mm}$-wide sections for culture.

As leaves did not develop in sterile culture, additional seeds were planted in a mixture of sand, vermiculite and soil in 1/10000a Wagner's pots (ICW-2, ICM Co. Ltd, Tsukuba, Japan) in a container and watered weekly. The plants of S. caseolaris were maintained in a green house in natural light conditions at $15-45^{\circ} \mathrm{C}$. After six months to three years of growth, the top four leaves of each plant were harvested. Leaves were washed with water and detergent, sterilized with $1 \% \mathrm{NaClO}$ for $30 \mathrm{~min}$ to $1 \mathrm{hr}$ and washed with sterile water three times. They were then cut into $1 \mathrm{~mm}$-wide sections in a manner similar to that for the cotyledons.

\subsection{Liquid Culture}

Disinfected cotyledons of S. caseolaris and S. alba, as well as hypocotyls and leaves of the former were cut in a Petri dish under axenic conditions. Two or three sections were placed in a $10 \mathrm{~mL}$ flat-bottomed culture tube (Maruemu No.3) with $1 \mathrm{~mL}$ liquid Murashige \& Skoog's (MS) [15] basal medium containing $0.1 \mu \mathrm{M}$ 2,4-di-chlorophenoxyacetic acid (2,4-D) and 3\% w/v of sucrose or glucose (when cited in text), and covered with autoclaved translucent film (BioHazard Bag 86.1199, Assist Co. Ltd.). The $\mathrm{pH}$ was adjusted to 5.8 before sterilization at $121^{\circ} \mathrm{C}, 20 \mathrm{~min}$. All cultures were incubated in the dark at $30^{\circ} \mathrm{C}$ on a rotary shaker at $100 \mathrm{rpm}$. When cited in the text, $10,12.5,25,50,100$, or $200 \mathrm{mM}$ of $\mathrm{KCl}, \mathrm{NaCl}$, $\mathrm{CaCl}_{2}, \mathrm{MgCl}_{2}$, or $\mathrm{MgSO}_{4}$ was added to the above media. Sorbitol, mannitol or glycinebetaine at 25, 50, 100, 200 or $400 \mathrm{mM}$ were also added. The cultures were observed under an inverted microscope (Olympus CK40).

\subsection{Data Description}

In S. caseolaris, two methods of quantifying the degree of cell proliferation were used. First, the total area of proliferated mass per explant was calculated using the image analysis program, Image $\mathbf{J}[16]$ to analyze digital photographs taken through the inverted microscope (Fig. 1). As this method is limited to a single two-dimensional representation of each cell mass, we also described cell proliferation at the cut surface of the explants in terms of a system of grades based on direct observation under an inverted microscope. In S. caseolaris, Grado 0, flat surface with no reaction; Grade 1, one cell layer appeared from the cut surface; Grade 2, two or three cells layers were present; Grade 3, 4-5 layers of proliferated cells could be found on the cut surface but the area of proliferation was more localized; Grade 4, 4-5 cells layer of proliferated cells covering a larger area of the cut surface; and Grade 5, more proliferation than 4. In S. alba, proliferation from both cut surfaces was assessed in assigning the numbers of grade $(0,1-4)$. All data were averaged per explant from data of 4 to 8 explants in 2 to 4 tubes. A student $\mathrm{t}$-test was performed on the difference of mean values between the control (i.e. without added salts and osmotic compounds) and each treatment at $\mathrm{P}<0.05$. 


\section{Results}

In the liquid culture of $S$. caseolaris, cell proliferation was observed at the cut surface of sections under an inverted microscope (Figures 1(a)-(c)). A freehand-traced area of cell proliferation (Figure 1(b), (c)) was measured from the photographs taken of each explant using the Image $\mathrm{J}$ program.

The effects of $\mathrm{KCl}, \mathrm{NaCl}, \mathrm{CaCl}_{2}$, and $\mathrm{MgCl}_{2}$ on cell proliferation from leaves (Figure 2) and cotyledons (Figure 3) of $S$. caseolaris were investigated. The total area of proliferation in controls was $0.63 \mathrm{~mm}^{2} /$ leaf explant (Figure 2) and $0.53 \mathrm{~mm}^{2} /$ cotyledon explant (Figure 3).

Low concentrations of $\mathrm{MgCl}_{2}(12.5 \mathrm{mM}$ and $25 \mathrm{mM})$ applied to leaves stimulated cell proliferation approximately 1.5-2.5-fold. No increase in cell proliferation was observed in leaves treated with $\mathrm{KCl}, \mathrm{NaCl}$ and $\mathrm{CaCl}_{2}$. In cotyledons, concentrations of $\mathrm{MgCl}_{2}$, from 12.5 to 100 $\mathrm{mM}$, increased cell proliferation approximately 2-3-fold over the control, while no clear stimulation was observed by $\mathrm{KCl}, \mathrm{NaCl}$ and $\mathrm{CaCl}_{2}$. All four salts tested were inhibitory at $200 \mathrm{mM}$ (Figure 3).

Asterisk on the top of bars in Figures 3 to 7 showed that differences were found at $\mathrm{p}<0.05$ by t-test. From the mean values of grade of reaction, percentages of stimulation or inhibition compared to zero control were calculated.

Effects of $\mathrm{KCl}, \mathrm{NaCl}, \mathrm{CaCl}_{2}$ and $\mathrm{MgCl}_{2}$ on cell proliferation from cotyledons of $S$. alba in a liquid culture were investigated (Figure 4). At zero concentration (the control of no additional salts), the grade of reaction was $2.6 \pm 0.28$ (S.E.)/explant. Low concentration $(10 \mathrm{mM})$ of $\mathrm{KCl}$ strongly $(80 \%)$ stimulated cell proliferation. No inhibition was observed at a wide range of $\mathrm{NaCl}$ concentrations (10-50 mM). Stimulation by $\mathrm{MgCl}_{2}$ was not observed and inhibition by $\mathrm{CaCl}_{2}$ was prominent. All salts at $200 \mathrm{mM}$ totally inhibited growth.

Effects of $\mathrm{KCl}, \mathrm{NaCl}, \mathrm{CaCl}_{2}, \mathrm{MgCl}_{2}$ on cell proliferation from hypocotyls of $S$. caseolaris were investigated (Figure 5). The grade of reaction of the zero control was $2.3 \pm 0.25$ (S.E.)/hypocotyl explant. Low concentrations of $\mathrm{MgCl}_{2}(12.5-25 \mathrm{mM})$ stimulated cell proliferation (44-111\%), in a manner similar to that of cotyledons of $S$. caseolaris (Figure 3) but different from cotyledons of $S$. alba, in which $\mathrm{MgCl}_{2}$ did not stimulate cell proliferation (Figure 4). Intermediate concentrations $(25-50 \mathrm{mM})$ of $\mathrm{NaCl}(44-67 \%)$ and $\mathrm{CaCl}_{2}$ (44-56\%) stimulated cell proliferation. Tolerance at $200 \mathrm{mM} \mathrm{NaCl}$ was also observed.

Since magnesium ions were effective in causing cell proliferation in S. caseolaris leaf explants (Figure 2), two different magnesium salts, i.e. $\mathrm{MgCl}_{2}$ and $\mathrm{MgSO}_{4}$, were tested to assess the effects of anions (Figure 6).

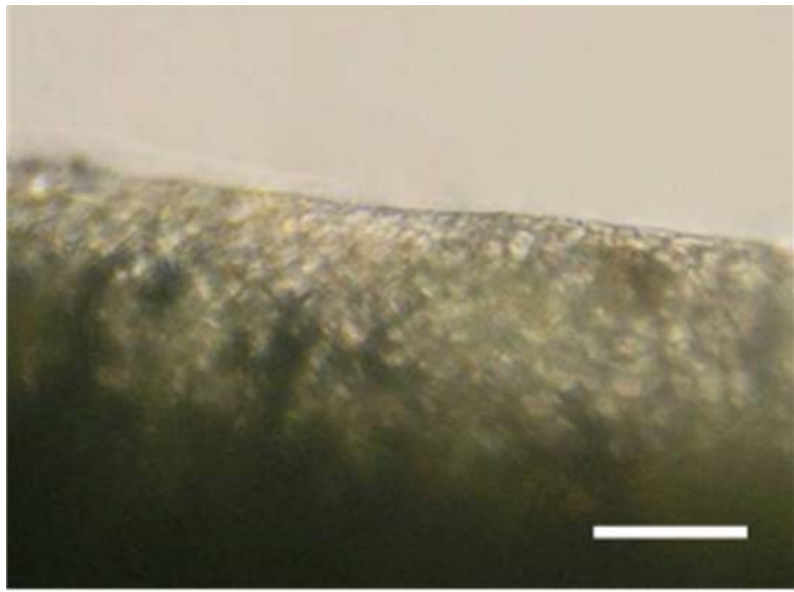

(a)

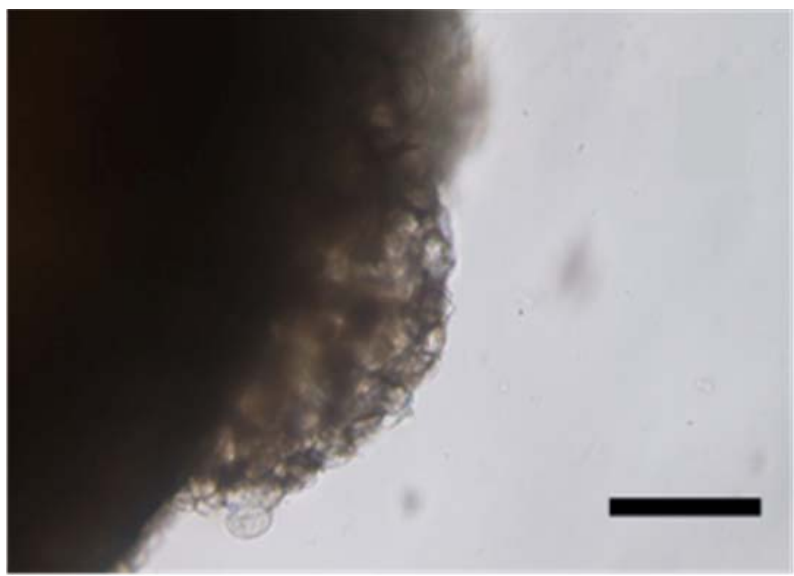

(b)

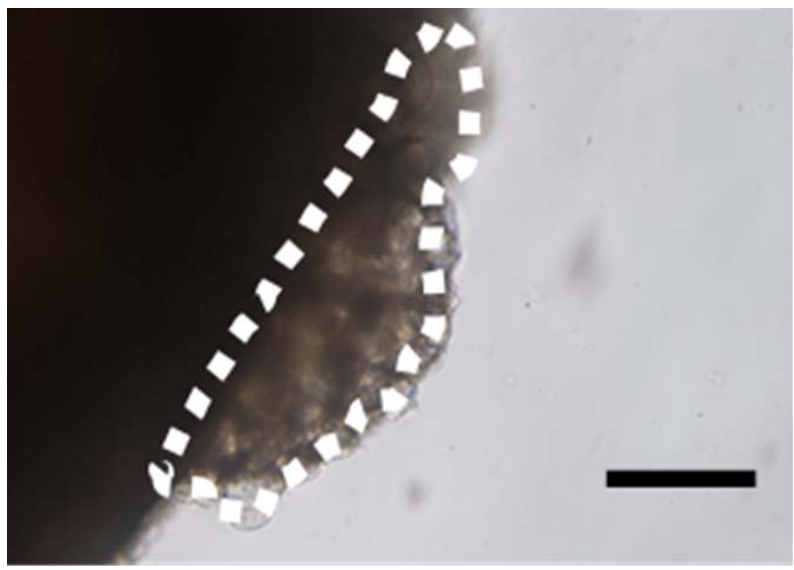

(c)

Figure 1. Measurement of the area of cell proliferation in liquid cultures of $S$. caseolaris leaf explant. (a) Cut surface before culture. (b) Proliferation of cells from the cut surface. (c) Area of proliferation from (b) was freehand-traced and its area was measured using the image analysis program, Image J. bar $=\mathbf{2 5 0} \mu \mathrm{m}$. 


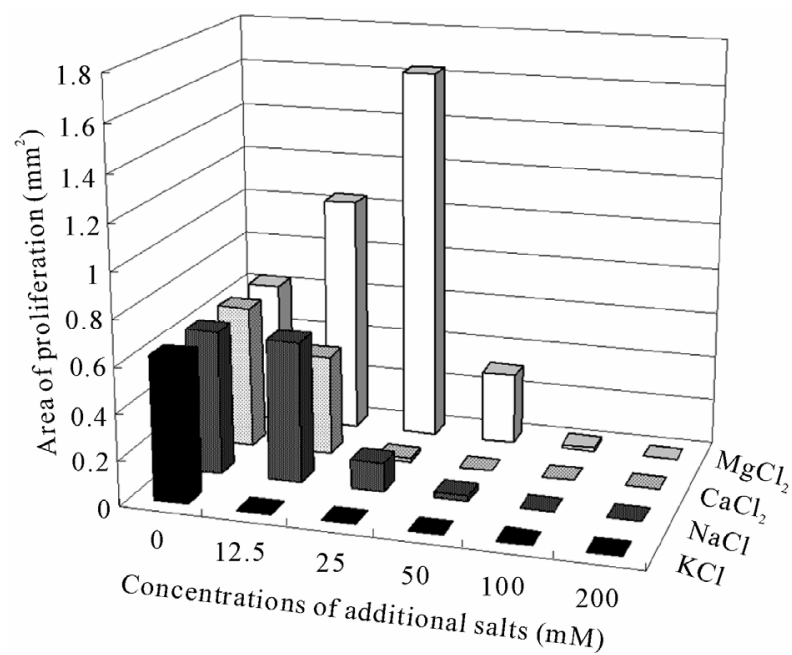

Figure 2. Effects of $\mathrm{KCl}, \mathrm{NaCl}, \mathrm{CaCl}_{2}$ and $\mathrm{MgCl}_{2}$ on induction of cell proliferation from leaves of $S$. caseolaris. Data were area of proliferation. Days of culture were 32 .

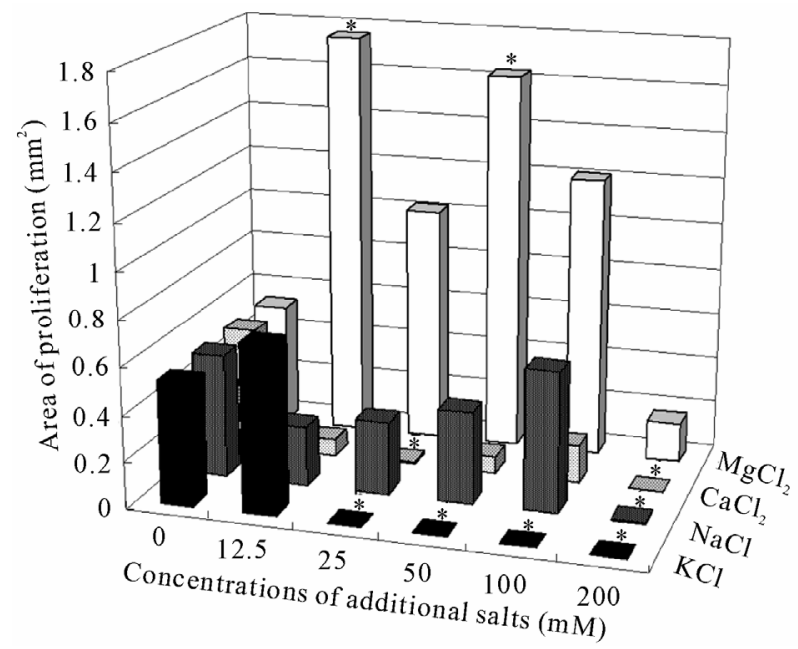

Figure 3. Effects of $\mathrm{KCl}, \mathrm{NaCl}, \mathrm{CaCl}_{2}$ and $\mathrm{MgCl}_{2}$ on cell proliferation from cotyledons of $S$. caseolaris. Data were area of proliferation. Days of culture were 34 .

Both formats of data description (area of proliferation in Figure 6(a) and the grade of proliferation in Figure 6(b)) showed similar results, except for the reaction to $\mathrm{MgSO}_{4}$ at $200 \mathrm{mM}$. At zero control, the area of proliferation was $1.03 \pm 0.29$ (S.E.) $\mathrm{mm}^{2} /$ explant (Figure 6(a)) and number of grade was $1.9 \pm 0.31$ (S.E.)/explant (Figure 6(b)). Low concentrations (12.5-25 $\mathrm{mM})$ of $\mathrm{MgCl}_{2}$ stimulated cell proliferation from leaf explants, though the percentage of stimulation (70\%) was lower than that of Figure 2, while less stimulation (23-50\%) was obtained with $\mathrm{MgSO}_{4}$. High concentrations (100-200 $\mathrm{mM}$ ) of $\mathrm{MgCl}_{2}$ were inhibitory, however, no inhibitory effect was observed at up to $100 \mathrm{mM}$ of $\mathrm{MgSO}_{4}$. When $3 \%$ glucose was used

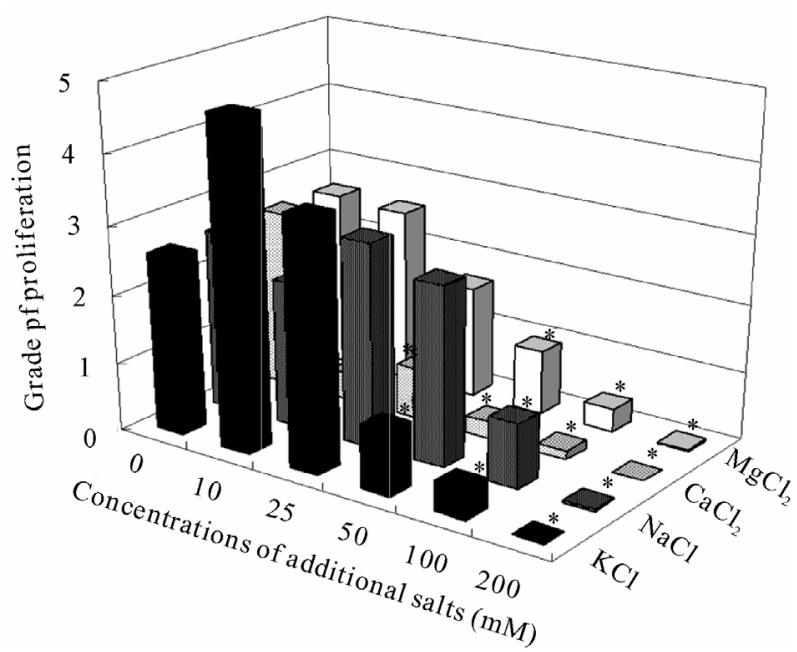

Figure 4. Effects of $\mathrm{KCl}, \mathrm{NaCl}, \mathrm{CaCl}_{2}$ and $\mathrm{MgCl}_{2}$ on cell proliferation from cotyledons of $S$. alba. Data were the grade of proliferation. Days of culture were 34 .

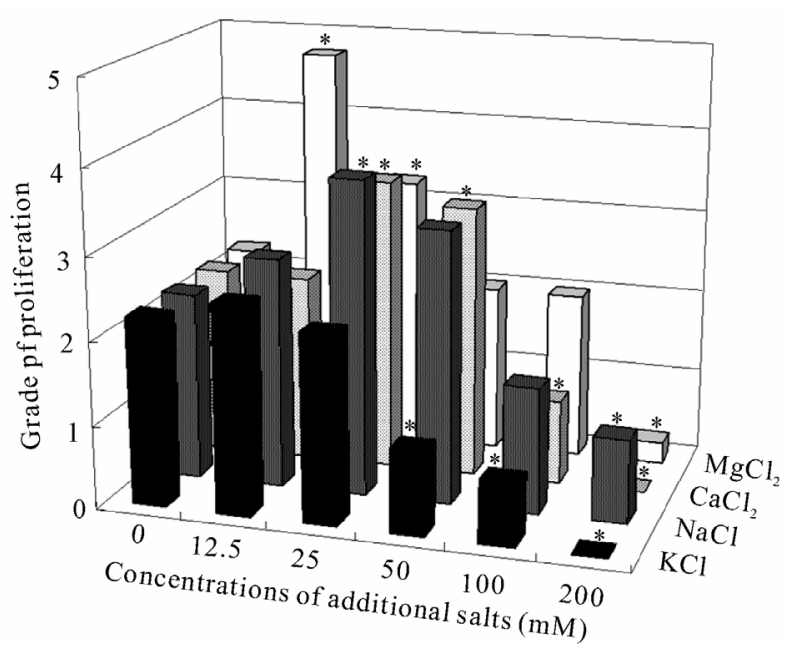

Figure 5. Effects of $\mathrm{KCl}, \mathrm{NaCl}, \mathrm{CaCl}_{2}$ and $\mathrm{MgCl}_{2}$ on cell enlargement and proliferation from hypocotyls of $S$. caseolaris. Data were the grade of proliferation. Days of culture were 48.

instead of sucrose in the medium, a clear stimulation (58-163\%) by low to intermediate concentrations (12.5$50 \mathrm{mM}$ ) of $\mathrm{MgCl}_{2}$ and tolerance at high concentration of $\mathrm{MgSO}_{4}$ were also observed (Figure 6(c)) . The number of grade of proliferation was $1.6 \pm 0.19$ (S.E.)/explant without additional salts.

The effects of different osmotic compounds in liquid cultures on leaves of S. caseolaris were investigated (Figure 7). The grade of reaction at zero control was $2.3 \pm$ 0.4 (S.E.)/leaf explant. The cultures could tolerate concentrations up to $100 \mathrm{mM}$. However, no clear stimulation of growth was observed. Both sorbitol and mannitol be- 

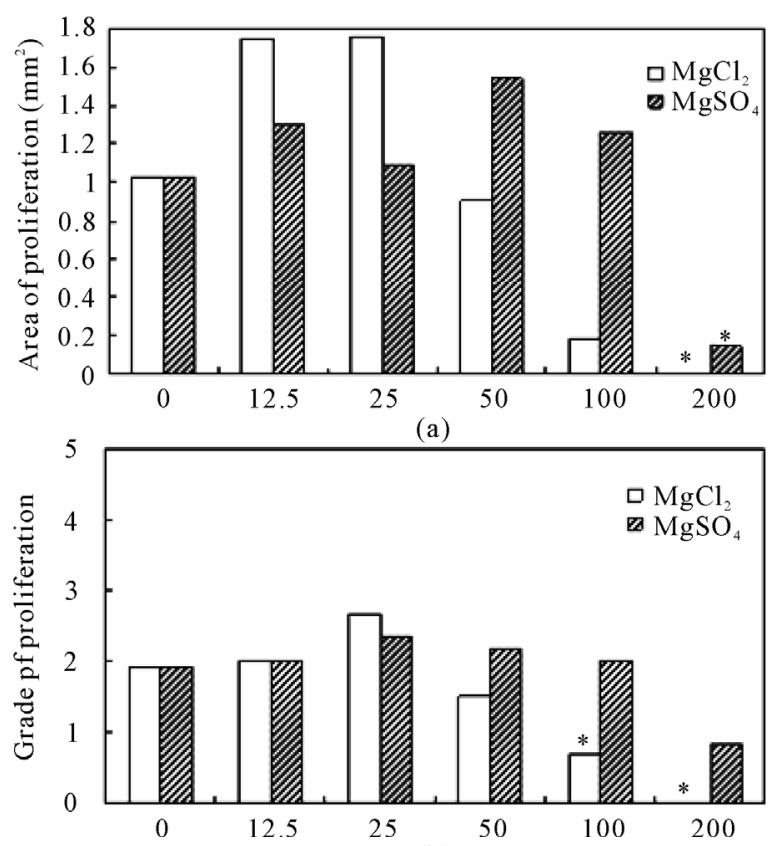

(b)

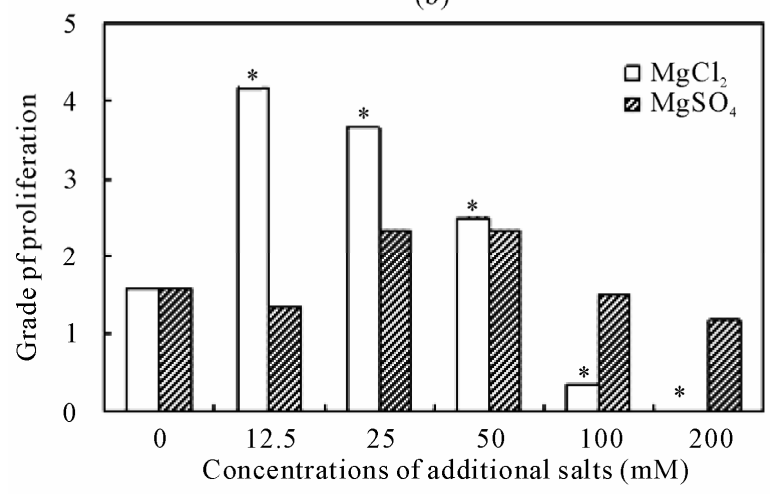

(c)

Figure 6. Comparison of the effects of $\mathrm{MgCl}_{2}$ and $\mathrm{MgSO}_{4}$ on cell proliferation from leaves of $S$. caseolaris. The control medium is MS containing $0.1 \mu \mathrm{M} 2,4-\mathrm{D}$ and $3 \%$ sucrose (a, b) and $3 \%$ glucose (c). Days of culture were 68 . Data were the area of proliferation (a) and grade of proliferation (b, c).

gan to produce significant inhibitory effects at $200 \mathrm{mM}$ and they became totally inhibitory to growth at $400 \mathrm{mM}$. When the effect of sorbitol in combination with $3 \%$ sucrose was investigated in liquid culture of cotyledons (Figure 8), the grade of reaction at zero control was $2.4 \pm$ 0.26 (S.E.)/cotyledon explant. Tolerance up to $200 \mathrm{mM}$ of sorbitol was observed and $400 \mathrm{mM}$ sorbitol was inhibitory. The pattern is very different from those of the four salts, i.e. $\mathrm{KCl}, \mathrm{NaCl}, \mathrm{MgCl}_{2}$ and $\mathrm{CaCl}_{2}$. Glycinebetaine totally inhibited growth in cultures of cotyledons and leaves of $S$. caseolaris at any concentrations (data not shown).

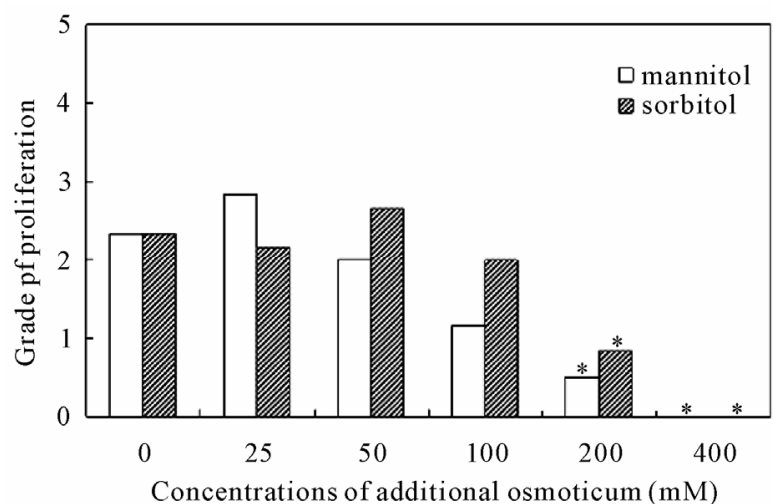

Figure 7. Effects of sorbitol and mannitol in combination with $3 \%$ sucrose on cell proliferation from leaves of $S$. caseolaris. Days of culture were 35. Data were the grade of proliferation.

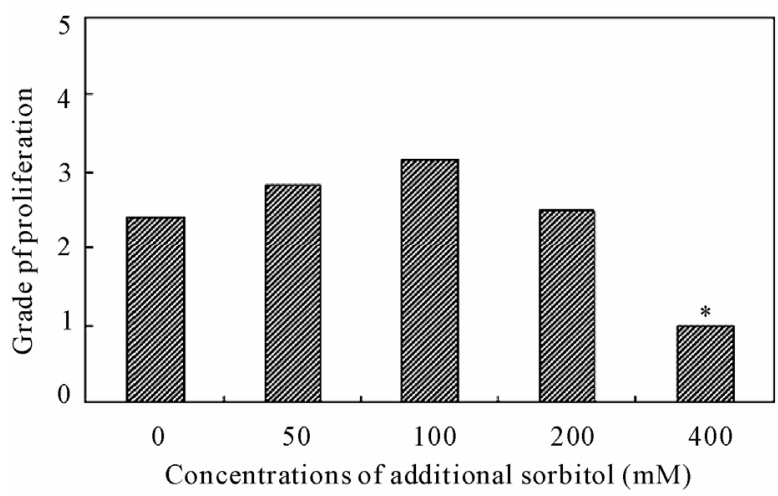

Figure 8. Effect of sorbitol in combination with $3 \%$ sucrose on cell proliferation from cotyledons of $S$. caseolaris. Data were the grade of proliferation. Days of culture were 37 .

\section{Discussion}

\subsection{Differences in Response to Added Salts between $S$. caseolaris and $S$. alba}

Tolerance to a wide range $(10-50 \mathrm{mM})$ of concentrations of $\mathrm{NaCl}$ was observed in cotyledon cultures of $S$. alba but not in cotyledon cultures of $S$. caseolaris. The fact that $S$. alba grows along the most seaside coast while $S$. caseolaris grows more in-land, may have contributed to the different responses observed. The salinity of the latter growing area was lower than that of the former [17]. In the suspension culture derived from cotyledons of S. alba, stimulation of growth was observed by $\mathrm{NaCl}$ at the same concentrations [12]. S. alba would have developed mechanisms to deal with the key component of sea water, i.e. sodium ions in order to achieve proper growth and development. Sea water and the mangrove growing soil contain substantial amount of other salts [18]. Induction 
of cell proliferation was greatly stimulated by $\mathrm{KCl}$ in cotyledon culture of S. alba but not in any of the S. caseolaris tissues. In the established suspension culture of $S$. $a l b a$, increase of growth was obtained at low concentration $(10 \mathrm{mM})$ of $\mathrm{KCl}$ [12]. On the contrary, low concentrations $(12.5-25 \mathrm{mM})$ of $\mathrm{MgCl}_{2}$ greatly stimulated cell induction from all three tissues in S. caseolaris, but not in the cotyledons of S. alba. No data of hypocotyls or leaves of $S$. alba were available in this report, because the growth of big seedlings was difficult in S. alba. To explore the mechanisms of salts tolerance, the development of in vitro culture systems is important for complementation of whole plant studies. S. alba and S. caseolaris are two excellent mangrove species of the same genera showing different responses to different salts. These can be cultured in the same MS basal medium containing $3 \%$ of sucrose and $0.1 \mu \mathrm{M}$ of $2,4-\mathrm{D}$, while modified amino acid basal medium was employed for the culture of B. sexangula of different family [8].

\subsection{Differences in Tissue Responses to Salts in S. caseolaris}

Differences were found in the reaction to different salts depending on the source of tissue tested, i.e. leaves, cotyledons, or hypocotyls. Stimulation by $\mathrm{NaCl}$ was observed in cultures of hypocotyls, but not in cotyledons or leaves. Similarly, $\mathrm{CaCl}_{2}$ was stimulatory to hypocotyl culture but had little effect on other tissues of $S$. caseolaris. Cotyledons and hypocotyls were more tolerant to $\mathrm{MgCl}_{2}$ than leaves. In nature, young seedlings of Sonneratia species sometimes grow under water but leaves are rarely submerged. Thus, we would expect cotyledons and hypocotyls to be more tolerant tissues to salty water than leaves. The observed difference in tolerance to $\mathrm{NaCl}$ depending on the origin of tissues, i.e. viviparous seedlings and leaves, was also reported for callus induction of B. sexangula [7].

Effects of salts can be explained partly as the osmotic effects of component ions. However, $\mathrm{MgCl}_{2}$ and $\mathrm{CaCl}_{2}$ were not always inhibitory compared to $\mathrm{NaCl}$ and $\mathrm{KCl}$ [12], implying that cations themselves are important in mangrove cells.

This is the first report where effects of high concentrations of $\mathrm{MgSO}_{4}$ were investigated, and tolerance of leaves of $S$. caseolaris was found in liquid culture, while low concentrations of $\mathrm{MgSO}_{4}$ were not stimulatory compared with $\mathrm{MgCl}_{2}$. Tolerance to $\mathrm{MgSO}_{4}$ was also found in media containing glucose (Figure 6(c)), which sugar stimulated cell proliferation from leaves of $S$. caseolaris in solid culture [19]. Although differences in ion dissociation can result in different osmotic potentials, the results in Figure 6 suggest anions may have specific roles to play. Both anions are ingredients of sea water and further studies are needed to ascertain their function.

\subsection{Effects of Osmotic Compounds in S. caseolaris}

The presence of salts naturally found in sea water can change the osmotic environment surrounding plants. Changes in the osmotic environment have a substantial effect on plant growth and development. It has been shown that osmotic stress enhances somatic embryo formation in carrot [20] and mannitol can induce somatic embryogenesis in vegetative tissues of Arabidopsis [21]. In this study, several common osmotica were used to assess the importance of the osmotic environment on cell proliferation of mangrove species. As shown in Figure 7, neither mannitol nor sorbitol had a significant stimulatory effect on cell proliferation of S. caseolaris, and became inhibitory to growth at $200 \mathrm{mM}$. In leaf culture of a Rhizophoraceae mangrove, Rhizophora stylosa, sorbitol at $0.2-0.4 \mathrm{M}$ was stimulatory for callus induction, while $\mathrm{NaCl}$ was inhibitory at the same osmotic potential [22]. Mannitol and glycinebetaine are known as naturally occurring osmotica in S. alba [23] and an Avicenniaceae mangrove, Avicennia marina [24], respectively. The glycinebtaine had a negative effect on growth even at low concentrations (data not shown). These suggest that changes in osmotic conditions alone are not sufficient to promote growth. The effects of salts cannot be described only by their effects as osmoticum. Both cations and anions of various salts may have specific functions to play in promoting growth and development of mangrove plants.

\subsection{Data Description Method}

In this report, in addition to recording the response as the numbers of grade of proliferation, which was used in the previous report in culture of S. alba [11], we introduced another data description method, the area of cell proliferation measured using an image analysis program. No critical difference in the effects of salts was found between two methods of data description. Although both methods yielded similar results, the grade method is preferred as one can identify small changes in the explant, especially at high salt concentrations, and the standard errors were smaller than the area method. The area method can only account for two dimensional changes in an explant and the process is time consuming. The use of small volume culture method as detailed in this study enables the assessment of changes of explants to different tested variables. Since the sources of seed materials are limited, this greatly increases the efficiency of the study. 


\subsection{Conclusions}

Mangrove plants have adapted to grow in an environment with high salts. This unique property is also reflected in the cell cultures generated from the mangrove species, Sonneratia caseolaris and S. alba. The ability of mangrove cell cultures to grow in the presence of high salts indicates the unique adaptation and metabolism of mangrove cells. It is important to note that different sea water components, $\mathrm{KCl}, \mathrm{NaCl}, \mathrm{CaCl}_{2}, \mathrm{MgCl}_{2}$ and $\mathrm{MgSO}_{4}$, elicit different responses from different mangrove species. This result indicates that different mangrove species have different metabolic adaptations to various salts in the environment. The ability of both mangrove species to tolerate high levels of magnesium ions indicates that magnesium ions may have a vital metabolic role to play within mangrove cells. Cell cultures generated from different tissues of the same plant react differently to various salts and salt concentrations. This observation suggests that different tissue types within the plant body responds to salts differently. Future biochemical and cell biological studies will provide further insight into the role of various ions on the growth of mangrove cultures.

\section{Acknowlegements}

Authors thank Prof. K. Suzuki of the Yokohama National University for his kind supply of the fruits of S. caseolaris. Authors also thank Prof. E. C. Yeung of the University of Calgary for his critical reading of this manuscript.

\section{REFERENCES}

[1] P. B. Tomlinson, "The Botany of Mangroves," Cambridge University Press, Cambridge, 1986.

[2] S. Ogita, E. C. Yeung, H. Sasamoto, "Histological analysis in shoot organogenesis from hypocotyls explants of Kandelia candel (Rhizophoraceae)," Journal of Plant Research, Vol. 117, No. 6, December 2004, pp. 457-464. doi:10.1007/s10265-004-0180-4

[3] H. Sasamoto, Y. Wakita, S. Yokota, N. Yoshizawa, T. Katsuki, Y. Nishiyama, T. Yokoyama, M. Fukui, "Effects of electric cell fusion treatment among leaf protoplasts of Populus alba and Alnus firma on growth, leaf morphology, and RAPD pattern of eleven acclimatized plants," In Vitro Cellular and Developmental Biology Plant, Vol. 42, No. 2, March 2006, pp. 174-178. doi:10.1079/IVP2005732

[4] Y. Kawana, H. Sasamoto, Y. Mochida, K. Suzuki, "Leaf protoplast isolation from eight mangrove species of three different families; Avicenniaceae, Rhizophoraceae and Sonneratiaceae," Mangrove Science, Vol. 3, October 2004, pp. 25-31.

[5] F. Kaai, Y. Kawana, H. Sasamoto, "The relation between recalcitrancy of a mangrove plant, Kandelia obovata, and high endogenous level of abscisic acid," Plant Cell Tissue and Organ Culture, Vol. 94, No. 2, August 2008, pp. 125-130. doi:10.1007/s11240-008-9394-9

[6] FAO, "Global network on integrated soil management for sustainable use of salt-affected soils," FAO Land and Plant Nutrition Management Service, 2005. http://www.fao.org/ag/AGL/agII/spush/

[7] T. Mimura, M. Mimura, S. Washitani-Nemoto, K. Sakano, T. Shimmen, S. Siripatanadilok, "Efficient callus initiation from leaf of mangrove plant, Bruguiera sexangula in amino acid medium: Effect of $\mathrm{NaCl}$ on callus initiation," Journal of Plant Research, Vol. 110, No. 1, March 1997, pp. 25-29. doi:10.1007/BF02506839

[8] M. Kura-Hotta, M. Mimura, T. Tsujimura, S. Washitani-Nemoto, T. Mimura, "High salt-treatment-induced $\mathrm{Na}+$ extrusion and low salt-treatment-induced $\mathrm{Na}+$ accumulation in suspension-cultured cells of the mangrove plant Bruguiera sexangula," Plant Cell and Environment, Vol. 24, No. 10, October 2001, pp. 1105-1112. doi:10.1046/j.0016-8025.2001.00761.x

[9] H. Sasamoto, S. Ogita, T. Mimura, "Cell fusion and protoplast cultures in a mangrove plant, Bruguiera sexangula," in Japanese. Proceedings of $111^{\text {th }}$ Annual Meeting of the Japanese Forrest Society, April 2000, p. 603.

[10] A. Yamada, T. Saitoh, T. Mimura, Y. Ozeki, "Expression of mangrove allene oxide cyclase enhances salt tolerance in Escherichia coli, yeast, and tobacco Cells," Plant Cell Physiology, Vol. 43, No. 8, August 2002, pp. 903-910. doi:10.1093/pcp/pcf108

[11] Y. Kawana, R. Yamamoto, Y. Mochida, K. Suzuki, S. Baba, H. Sasamoto, "Generation and maintenance of suspension cultures from cotyledons and their organogenic potential of two mangrove species, Sonneratia alba and S. caseolaris," Plant Biotechnology Reports, Vol. 1, No. 4, November 2007, pp. 219-226. doi:10.1007/s11816-007-0035-2

[12] Y. Kawana, H. Sasamoto, "Stimulation Effects of Salts on Growth in Suspension Culture of a Mangrove Plant, Sonneratia alba, Compared with Another Mangrove, Bruguiera sexangula and Non-Mangrove Tobacco BY-2 cells," Plant Biotechnology, Vol. 25, No. 2, May 2008, pp. 151-155. doi:10.5511/plantbiotechnology.25.151

[13] A. Miyawaki, K. Suzuki, S. Suzuki, Y. Nakamura, Y. Murakami, Y. Tukagoshi, E. Nakata, "Phytosociological studies of mangrove vegetation in Japan. 1. Mangrove vegetation of Iriomote island," Bull. Inst. Envir. Sci. Tech. Yokohama Nat. Univ. Vol. 9, 1982, pp. 77-89.

[14] A. Miyawaki, S. Okuda, K. Suzuki, K. Fujiwara, Y. Nakamura, Y. Murakami, K. Ohno, S. Suzuki, S. Sabhasri, "Phytosociological studies of mangrove vegetation in Thailand. In: A. Miyawaki, ed., Ecological studies on the vegetation of mangrove forests in Thailand, Published by Dept. of Vegetaion Science, Inst. Envir. Sci. Tech. Yokohama Nat. Univ., Yokohama, Japan, 1985.

[15] T. Murashige, F. Skoog, "A revised medium for rapid growth and bioassay with tobacco tissue cultures," 
Physiol Plant, Vol. 15, No. 3, July 1962, pp. 473-497. doi:10.1111/j.1399-3054.1962.tb08052.x

[16] Image J, NIH, USA, Internet Available: http://rsb.info.nih.gov/ij/

[17] N. C. Duke, "Mangrove floristics and biogeography," In: A.I. Robertson, D.M. Alongi, Eds., Tropical mangrove ecosystems, American Geophysical Union, Washington, 1992, pp. 63-100.

[18] T. Fukumoto, T. Nakamura, M. Suzuki, S. Ogita, T. Mimura, H. Sasamoto, "Different effects of four salts and $\mathrm{pHs}$ on protoplast cultures of a mangrove, Bruguiera sexangula suspension cells, Populus alba leaves and tobacco BY-2 cells," Plant Biotechnology, Vol. 21, No. 3, September 2004, pp. 177-182. doi:10.5511/plantbiotechnology.21.177

[19] R. Yamamoto, Y. Kawana, R. Minagawa, H. Sasamoto, "Effects of carbon and nitrogen sources on induction of cell proliferation in tissue cultures of a mangrove plant, Sonneratia caseolaris," Mangrove Science, Vol. 6, January 2009, pp. 1-8.

[20] H. Kamada, K. Ishikawa, H. Saga, H. Harada, "Induction of somatic embryogenesis by osmotic stress in carrot," Plant Tissue Culture Letters, Vol. 10, No. 1, April 1993, pp. 38-44.

[21] M. Ikeda-Iwai, M. Umehara, S. Satoh, H. Kamada, "Stress-induced somatic embryogenesis in vegetative tissues of Arabidopsis thaliana," Plant Journal, Vol. 34, No.1, April 2003, pp. 107-114. doi:10.1046/j.1365-313X.2003.01702.x

[22] Y. Kawamitsu, K. Tokumaru, "Examination of the optimum callus induction medium in Rhizophora stylosa," in Japanese. In: Reports of Research Institute for Subtropics, 2003, pp. 193-202.

[23] E. Yasumoto, K. Adachi, M. Kato, H. Sano, H. Sasamoto, S. Baba, H. Ashihara, "Uptake of inorganic ions and compatible solutes in cultured mangrove cells during salt stress," In Vitro Cellular Developmental Biology Plant, Vol. 35, No. 1, January1999, pp. 82-85. doi:10.1007/s11627-999-0015-Z

[24] H. Ashihara, K. Adachi, M. Otawa, E. Yasumoto, Y. Fukushima, M. Kato, H. Sano, H. Sasamoto, S. Baba, "Compatible solutes and inorganic ions in the mangrove plant Avicennia marina and their effects on the activities of enzymes," Zeitschrift fur Naturforschung, Vol. 52c, No. 5/6, May 1997, pp. 433-440. 